\title{
PENYEDIAAN RUANG TERBUKA HIJAU PUBLIK BERKONSEP GREEN ARCHITECTURE DI KAMPUNG TUA TANJUNG RIAU
}

\author{
${ }^{1}$ Carissa Dinar Aguspriyanti, ${ }^{2}$ Devin Tan, ${ }^{3}$ Indah Yunita \\ 1-3Universitas Internasional Batam, Batam, Indonesia \\ carissa@uib.ac.id ${ }^{1}$
}

\author{
Informasi Naskah \\ Diterima: 23/02/2021; Disetujui terbit: 14/06/2021; Diterbitkan: 30/06/2021; \\ http://journal.uib.ac.id/index.php/jad
}

\begin{abstract}
ABSTRAK
Kampung Tua Tanjung Riau merupakan perkampungan Melayu yang terdapat di Kota Batam, Kepulauan Riau. Seiring perkembangan zaman, rumah-rumah yang terdapat di Kampung Tua Tanjung Riau menjadi semakin padat dan mayoritas penduduk setempat mulai mengabaikan pentingnya ruang terbuka hijau (RTH). Padahal ruang terbuka hijau khususnya RTH publik merupakan kebutuhan wajib dalam pengembangan suatu permukiman, apalagi jika mengingat kondisi bumi yang sedang mengalami pemanasan global. Penelitian ini merupakan penelitian kualitatif dengan metode pendekatan analisis deskriptif. Hasil penelitian mencatat bahwa penyediaan ruang terbuka hijau (RTH) publik berkonsep green architecture dapat diwujudkan dengan mengoptimalkan ruang terbuka yang sudah ada di Kampung Tua Tanjung Riau. Aplikasi konsep green architecture yang ramah lingkungan dan berkelanjutan dapat melalui enam kriteria, antara lain hemat energi, mampu beradaptasi dengan iklim, tanggap terhadap tapak, memenuhi kebutuhan pengguna, meminimalisir penggunaan material baru, dan diaplikasikan secara menyeluruh.
\end{abstract}

Kata Kunci: ruang terbuka hijau, green architecture, Kampung Tua Tanjung Riau

\begin{abstract}
Kampung Tua Tanjung Riau is a Malay village located in Batam City, Riau Islands. Along with the times, the houses in Kampung Tua Tanjung Riau have become increasingly crowded and the majority of local residents have begun to less aware of the importance of green open spaces. Whereas green open space, particularly public green open space, is a mandatory requirement for a settlement development, given the current earth condition which is experiencing global warming. This research is a qualitative research with a descriptive analysis approach method. The results of this research highlight that the provision of public green open space with the concept of green architecture can be delivered by optimising the existing open space in Kampung Tua Tanjung Riau. The green architecture concept which is environmentally friendly and sustainable can be applied through six criteria, including conserving energy, working with climate, respect for site, respect for user, limiting new resources, and holistic.
\end{abstract}

Keywords: green open space, green architecture, Kampung Tua Tanjung Riau

\section{Pendahuluan}

Kampung Tua Tanjung Riau merupakan salah satu permukiman pesisir yang ada di Kota Batam, Kepulauan Riau. Sebagian besar penduduk Kampung Tua Tanjung Riau berprofesi sebagai nelayan, hal ini dikarenakan posisi wilayahnya yang dikelilingi lautan. Berlokasi tepat di sebelah area pantai, Kampung Tua Tanjung Riau memiliki potensi wisata bahari. Selain kondisi geografisnya, Kampung Tua Tanjung Riau juga memiliki sejarah budaya arsitektur Melayu, mengingat Kota Batam yang pada awalnya dihuni oleh mayoritas etnis Melayu. Rumah-rumah yang terdapat pada Kampung Tua Tanjung Riau memiliki 
keunikan yang terlihat pada bentuk rumah di permukiman tersebut. Ciri khas yang paling terlihat dari rumah-rumah yang terdapat di Kampung Tua Tanjung Riau adalah adanya beranda pada hampir setiap rumah dan material rumah yang sebagian besar masih menggunakan kayu.

Sebagai salah satu bagian dari Kota Batam yang masih mengandung nilai-nilai budaya Melayu, Kampung Tua Tanjung Riau harus dijaga dengan baik. Namun dalam perkembangannya Kampung Tua Tanjung Riau menjadi daerah permukiman yang cenderung kumuh karena tingkat kepadatan bangunan yang semakin tinggi dan kebersihan yang kurang dijaga oleh masyarakat setempat yang salah satunya disebabkan oleh faktor ketidaktersediaan sistem pengelolaan sampah yang optimal (Aguspriyanti et al., 2020). Studi sebelumnya juga menambahkan bahwa bentuk pola persebaran permukiman yang cenderung memanjang ke arah laut disertai dengan tingginya tingkat kepadatan bangunan di Kampung Tua Tanjung Riau menyebabkan terbatasnya ruang terbuka hijau publik layak yang tersedia (Aguspriyanti et al., 2021). Padahal ruang terbuka hijau merupakan suatu kebutuhan wajib bagi suatu permukiman mengingat kondisi bumi kita sekarang ini yang sedang mengalami pemanasan global. Selain karena tuntutan kondisi, ruang terbuka hijau juga memiliki manfaat yang cukup signifikan terhadap kondisi penghuni permukiman dan lingkungan sekitar, mulai dari meningkatkan kualitas udara yang berhubungan dengan kesehatan masyarakat hingga memberikan efek psikologis yang menyenangkan.

Sebagian besar penelitian yang sudah dilakukan di kawasan Kampung Tua Tanjung Riau membahas seputar aspek kekumuhan dan hal-hal lain yang berkaitan dengan permasalahan permukiman pesisir setempat. Belum ada penelitian atau rencana pengembangan yang berkaitan dengan ruang terbuka hijau publik di kawasan tersebut. Oleh karena itu, diperlukan kajian rencana penyediaan ruang terbuka hijau publik di Kampung Tua Tanjung Riau, yang dapat meminimalisir dampak negatif terhadap lingkungan, melestarikan kearifan lokal Melayu, dan berkelanjutan. Desain berkelanjutan ini dapat diwujudkan melalui konsep green architecture.

\section{Kajian Pustaka}

\subsection{Pentingnya Ruang Publik}

Menurut Rustam Hakim (1987), ruang publik merupakan ruang atau wadah yang dapat menampung aktivitas masyarakat secara individu maupun berkelompok. Bentuk ruang publik ini dapat berupa ruang publik yang terbuka dan tertutup. Umumnya, ruang publik yang terbuka identik dengan aktivitas-aktivitas outdoor, salah satu contohnya adalah ruang terbuka hijau publik. Plato menambahkan definisi dari ruang terbuka merupakan suatu wadah yang tidak memiliki penutup secara fisik yang berfungsi mewadahi aktivitas masyarakat dan sebaiknya tidak dipisahkan dari masyarakat baik secara psikologis, emosional maupun dimensional (Rukayah, 2003).

Keberadaan ruang publik di suatu permukiman dinilai signifikan, khususnya sebagai wadah sosial masyarakat dan sarana komunikasi untuk melakukan aktivitas budaya, seperti yang diutarakan oleh Whyte dalam Hepcan et al. (2006). Tujuan ideal dari ruang publik agar masyarakat dapat melakukan interaksi saling bertukar ide bahkan anak-anak dapat memiliki ruang bermain. Sempitnya ruang publik mengakibatkan adanya pembatas dalam suatu lapisan masyarakat yang dapat menumbuhkan sifat individualistik dan egois.

Oleh karena itu, keberadaan ruang publik yang terbatas merupakan salah satu bentuk bencana tidak langsung bagi suatu daerah, khususnya daerah permukiman dikarenakan

55 I 」AD-Vol.02/No.01, Juni 2021 
masyarakat umum menjadi tidak memiliki akses terhadap ruang di mana mereka berkesempatan untuk berinteraksi dan anak-anak menjadi tidak memiliki ruang untuk bermain.

\subsection{Manfaat Ruang Terbuka Hijau}

Salah satu permasalahan yang dominan pada daerah beriklim tropis adalah suhunya yang tinggi, apalagi saat ini bumi sedang mengalami pemanasan global. Zat-zat seperti aspal, semen, asap kendaraan, dan kepadatan bangunan dapat berkontribusi atas terjadinya peningkatan suhu di suatu daerah. Kehadiran ruang terbuka hijau (RTH) dapat membantu meminimalisir fenomena ini, menurunkan suhu dan meningkatkan kualitas udara di daerah tersebut, serta dapat menambah nilai estetika daerah tersebut (Nitdiawati, 2011).

Berdasarkan penelitian BMC Public Health (Bowler et al., 2010), melakukan aktivitas olahraga seperti berjalan atau berlari di ruang hijau menyebabkan penurunan emosi amarah, kelelahan serta perasaan depresi dan juga meningkatkan perhatian lebih dibandingkan melakukan aktivitas tersebut di lingkungan sintetis.

Di dalam Peraturan Menteri Pekerjaan Umum Nomor : 05/PRT/M/2008 (Direktorat Jenderal Penataan Ruang Departemen Pekerjaan Umum, 2008) disebutkan pula bahwa RTH di perkotaan dapat berperan penting dalam hal ekologis, sosial budaya, ekonomi, dan estetika. Fungsi ekologis dari RTH, sebagai fungsi utama, adalah menjadi bagian dari sistem sirkulasi udara, pengatur iklim mikro, sebagai peneduh, produsen oksigen, penyerap air hujan, penyedia habitat satwa, penyerap polutan media udara, air, dan tanah, serta penahan angin. Sedangkan fungsi sosial budaya dari RTH meliputi sarana penggambaran ekspresi budaya lokal, sebagai media komunikasi warga kota, tempat rekreasi, wadah dan objek pendidikan, penelitian, dan pelatihan dalam mempelajari alam. Di samping itu, RTH juga mampu memberikan manfaat dari segi ekonomi dan estetika, di mana RTH dapat menjadi wadah penyedia produk yang bisa dijual seperti buah dan sayur dan meningkatkan kenyamanan, serta memperindah lingkungan.

\subsection{Pendekatan Konsep Green Architecture dalam Penataan RTH Publik}

Tabel 1. Konsep Green Architecture

\begin{tabular}{|c|l|l|}
\hline No & \multicolumn{1}{|c|}{ Kriteria } & \multicolumn{1}{c|}{ Deskripsi } \\
\hline 1 & $\begin{array}{l}\text { Conserving } \\
\text { energy }\end{array}$ & $\begin{array}{l}\text { Meminimalisir penggunaan energi melalui } \\
\text { modifikasi iklim dan adaptasi dengan } \\
\text { lingkungan }\end{array}$ \\
\hline 2 & $\begin{array}{l}\text { Working with } \\
\text { climate }\end{array}$ & $\begin{array}{l}\text { Mengoptimalkan pemanfaatan kondisi alam } \\
\text { dan lingkungan sekitar serta iklim setempat }\end{array}$ \\
\hline 3 & $\begin{array}{l}\text { Respect for } \\
\text { site }\end{array}$ & $\begin{array}{l}\text { Menanggapi kondisi tapak dengan mengacu } \\
\text { pada interaksi obyek dengan tapaknya }\end{array}$ \\
\hline 4 & $\begin{array}{l}\text { Respect for } \\
\text { user }\end{array}$ & $\begin{array}{l}\text { Memperhatikan kondisi dan kebutuhan } \\
\text { pengguna }\end{array}$ \\
\hline 5 & $\begin{array}{l}\text { Limiting new } \\
\text { resources }\end{array}$ & $\begin{array}{l}\text { Mengoptimalkan material yang ada dengan } \\
\text { meminimalisir penggunaan material baru }\end{array}$ \\
\hline 6 & Holistic & $\begin{array}{l}\text { Menerapkan kelima poin di atas sebagai satu } \\
\text { kesatuan konsep yang utuh }\end{array}$ \\
\hline
\end{tabular}

Rukayah (2003) menyatakan bahwa green architecture merupakan suatu konsep 
arsitektur yang menaruh perhatian lebih terhadap lingkungan alam sekitarnya serta efek ekologi yang ditimbulkannya. Ekologi merupakan poin utama perhatian dalam konsep ini, serta dengan menggunakan efisiensi pada bangunan agar sebisa mungkin memakai energi dari alam supaya lebih menghargai lingkungan. Konsep green architecture ini melakukan desain pendekatan secara ekologis, dengan menggunakan tumbuhan maupun lingkungan alami untuk menyiasati keadaan serta menggunakan teknologi yang tidak berdampak buruk bagi manusia maupun lingkungan sekitarnya.

Green architecture juga memiliki prinsip untuk meminimalkan dampak dan pengaruh buruk terhadap manusia maupun alam dan menghasilkan lingkungan hidup yang lebih sehat dengan cara memanfaatkan sumber energi secara optimal dan efisien serta sumber daya alam lokal yang telah ada. Konsep green architecture secara garis besar dapat dilihat pada Tabel 1.

Konsep green umumnya diterapkan dalam merancang sebuah bangunan. Namun, konsep tersebut dapat dijadikan acuan pula dalam membuat konsep ruang terbuka hijau publik. Mira Dharma dan Aldy (2017) menunjukan bahwa beberapa aplikasi prinsip-prinsip green architecture dalam penataan sebuah kawasan di antaranya penggunaan panel surya, penerapan 3R (reuse, recycle, dan renewable), pengumpul air hujan, roof garden, dan penggunaan material lokal yang mampu memberikan efisiensi waktu dan energi.

Dharmadiatmika (2017) menambahkan contoh ruang terbuka hijau publik berkonsep green dalam penelitiannya, yang menunjukkan bahwa enam atribut hijau yang dapat diterapkan adalah green transportation, green waste, green water, green energy, green open space, dan green building. Jika melihat relasi dengan konsep green architecture dari Vale (1991), green transportation yang berfokus pada pengguna sejalan dengan konsep respect for user. Sedangkan, green waste, green water, dan green energy memiliki keterkaitan yang erat dengan aspek conserving energy. Selanjutnya, kriteria working with climate dan respect for site dapat diwujudkan melalui adanya green open space. Di sisi lain, ada green building yang berhubungan dengan limiting new resources dan menggunakan material-material yang ramah lingkungan.

\section{Metode Penelitian}

Penelitian ini merupakan penelitian kualitatif, dengan metode pendekatan analisis deskriptif yang bertujuan mendeskripsikan objek penelitian maupun hasil penelitian (Sugiyono, 2010) untuk memahami fenomena di wilayah penelitian. Penelitian dilakukan di kawasan permukiman pesisir Kampung Tua Tanjung Riau, Kota Batam. Kondisi pandemi Covid-19 membatasi teknik pengumpulan data yang dibutuhkan dalam penelitian ini. Data primer dan sekunder yang dikumpulkan bersumber dari hasil observasi atau pengamatan lapangan secara langsung dan pencarian referensi dari beberapa sumber, tanpa melibatkan wawancara penduduk atau pemerintah setempat. Setelah data-data tersebut terkumpul, dilanjutkan dengan proses analisis SWOT hasil pengamatan kondisi eksisting sebagai parameter dalam merencanakan konsep penyediaan ruang terbuka hijau publik di Kampung Tua Tanjung Riau.

\section{Hasil dan Pembahasan}

\subsection{Analisis Kondisi Eksisting}

Berdasarkan hasil temuan di lapangan, ditemukan bahwa kepadatan bangunan di permukiman pesisir Kampung Tua Tanjung Riau cukup tinggi sehingga hanya ada tiga

57 I JAD-Vol.02/No.01, Juni 2021 
ruang terbuka. Ruang terbuka tersebut antara lain RTH yang berfungsi sebagai lapangan sepakbola, ruang terbuka yang berfungsi sebagai lapangan masjid, dan ruang terbuka yang belum difungsikan secara khusus (Gambar 2). Dengan pertimbangan optimalisasi fungsi ruang, ruang terbuka yang belum memiliki fungsi tersebut berpotensi untuk dikembangkan menjadi RTH publik, dengan harapan ruang tersebut dapat digunakan secara maksimal oleh penduduk setempat. Kemudian dilakukan analisis SWOT terhadap kondisi eksisting site terpilih tersebut (Tabel 2).

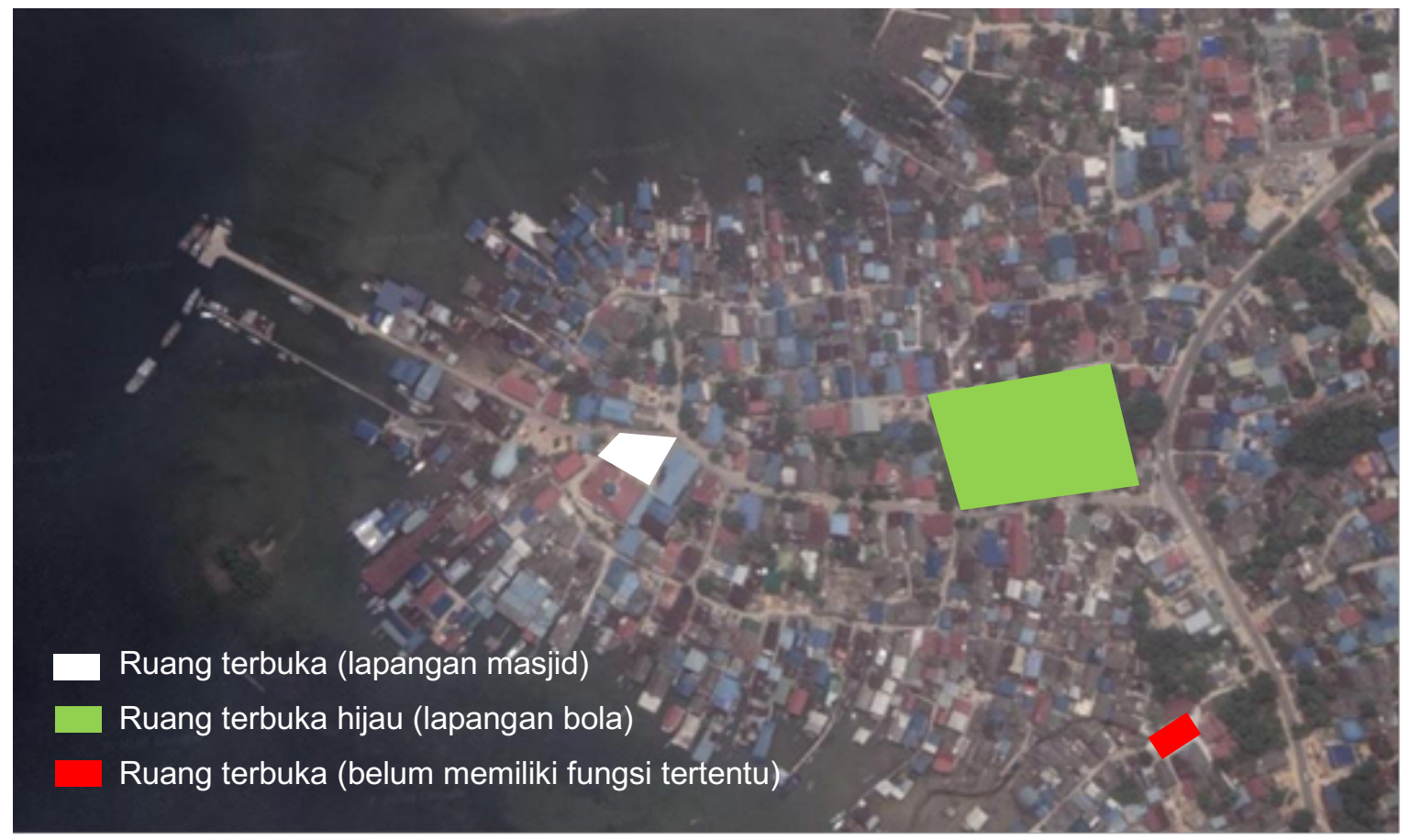

Gambar 1. Peta Sebaran Ruang Terbuka di Kampung Tua Tanjung Riau Sumber: Google Maps, 2021

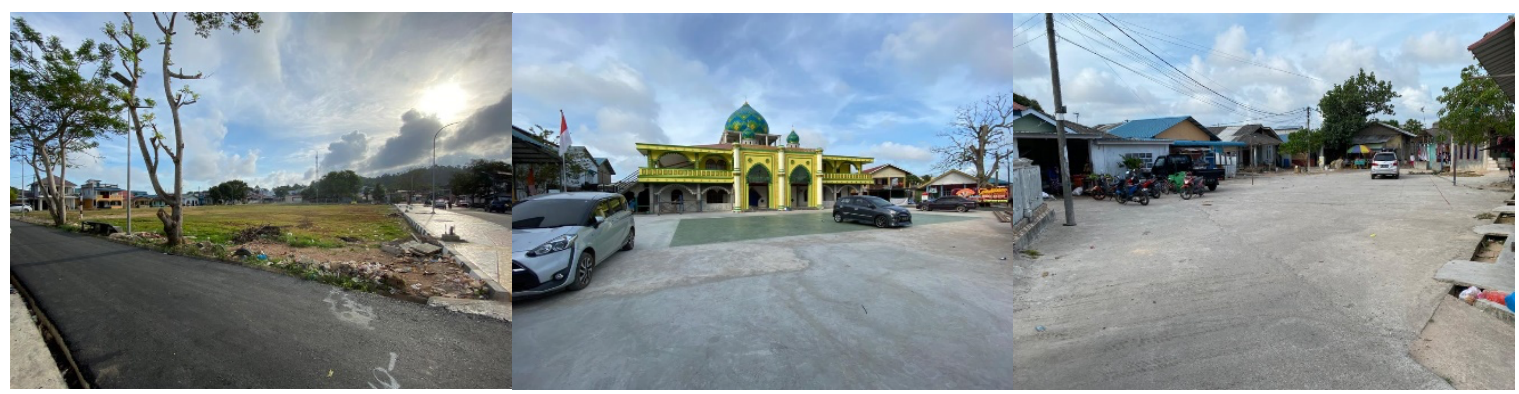

Gambar 2. Kondisi Eksisting Ruang Terbuka di Kampung Tua Tanjung Riau (Kiri-Kanan: Lapangan Bola, Lapangan Masjid, Ruang Terbuka yang Belum Memiliki Fungsi Tertentu) Sumber: Penulis, 2021

Tabel 2. Analisis SWOT Kondisi Eksisting Site Terpilih

\begin{tabular}{|c|l|l|}
\hline No & Kriteria & \multicolumn{1}{c|}{ Deskripsi } \\
\hline 1 & Strength & - Kondisi tapak relatif datar, tidak berkontur. \\
& & - Berada di kawasan permukiman yang cukup padat dan \\
& & ramai. \\
& & - Mudah diakses, baik dari jalan utama dan jalan \\
& & - Kermukiman. \\
& & Kondisi iklim tropis yang mendapatkan curah hujan dan \\
\hline
\end{tabular}




\begin{tabular}{|c|c|c|}
\hline & & sinar matahari yang cukup sepanjang tahun. \\
\hline 2 & Weakness & $\begin{array}{l}\text { - Resiko ketidaknyamanan pengguna ruang karena iklim } \\
\text { Batam yang relatif panas dengan paparan sinar matahari } \\
\text { yang cukup terik. } \\
\text { - Minimnya fasilitas publik di kawasan setempat. }\end{array}$ \\
\hline 3 & Opportunity & $\begin{array}{l}\text { - Dapat melibatkan seluruh area tapak dalam perencanaan } \\
\text { dengan lebih mudah tanpa banyak perubahan atau } \\
\text { pengaturan khusus } \\
\text { - Memanfaatkan sinar matahari sebagai alternatif sumber } \\
\text { energi dan pencahayaan alami. } \\
\text { - Memanfaatkan air hujan yang ditampung untuk dapat } \\
\text { digunakan kembali pada kawasan setempat. } \\
\text { - Dapat dilengkapi dengan fasilitas-fasilitas publik yang } \\
\text { belum ada di kawasan setempat. }\end{array}$ \\
\hline 4 & Threat & $\begin{array}{l}\text { - Diperlukan desain yang dinamis untuk meminimalisir efek } \\
\text { monoton dari kondisi tapak yang relatif datar. } \\
\text { - Pemilihan material yang dapat bertahan lama dengan } \\
\text { kondisi iklim tropis. }\end{array}$ \\
\hline
\end{tabular}

Sumber: Penulis, 2021

\subsection{Penerapan Konsep Green Architecture Pada Perencanaan RTH Publik}

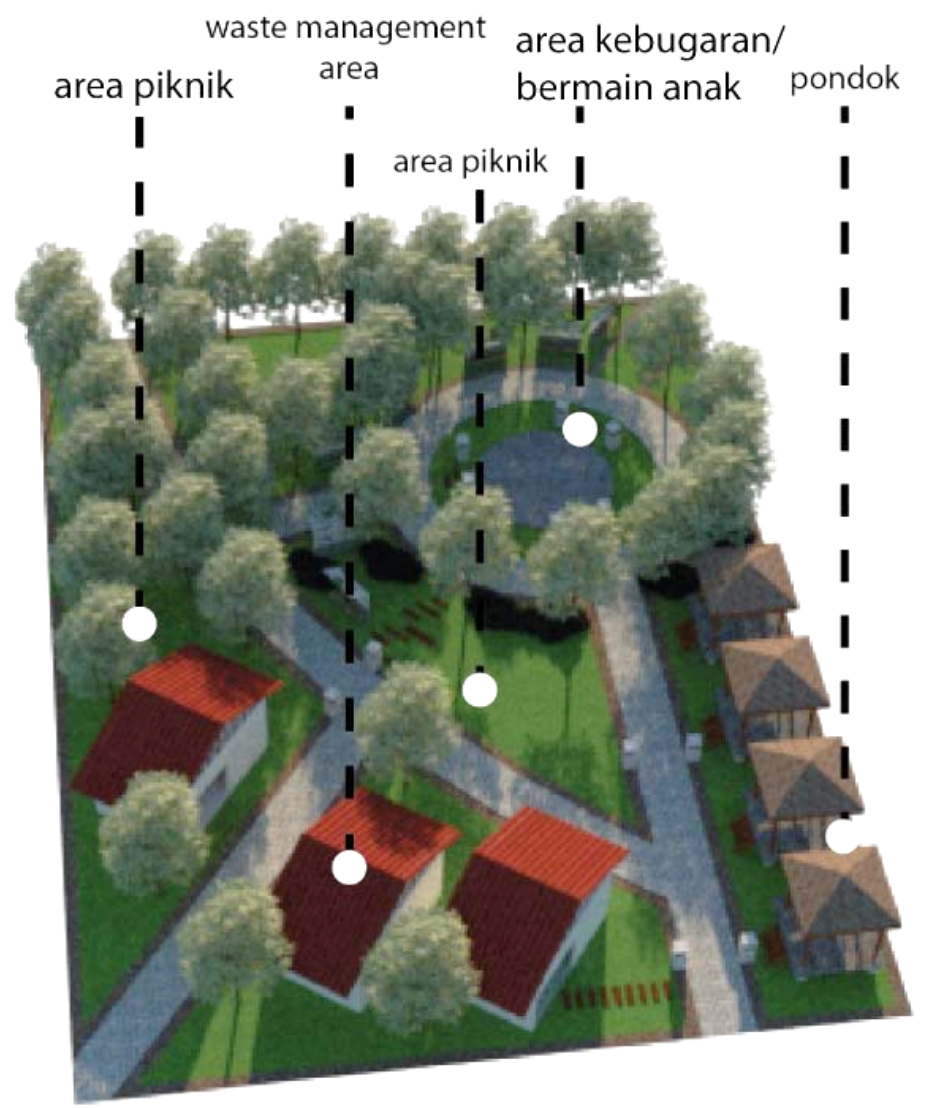

Gambar 3. Pembagian Area Ruang Terbuka Hijau Publik Sumber: Penulis, 2021 
Untuk menjawab permasalahan yang ada di Kampung Tua Tanjung Riau, khususnya yang berkaitan dengan fasilitas pengelolaan sampah, diperlukan adanya waste management di RTH publik yang direncanakan. Sehingga pengembangan ruang terbuka hijau di Kampung Tua Tanjung Riau terbagi atas beberapa area seperti waste management area, area pondok (gazebo), area kebugaran atau bermain anak, dan area piknik (Gambar 3). Kemudian, penerapan prinsip atau kriteria green architecture dapat dijabarkan sebagai berikut:

\section{- Conserving Energy}

Berdasarkan hasil analisis SWOT, bangunan di waste management area didesain dengan bukaan yang besar (Gambar 4) untuk menghemat energi dengan memanfaatkan cahaya matahari sebagai sumber pencahayaan utama. Pemilihan warna putih juga membantu untuk meningkatkan intensitas cahaya. Lampu-lampu taman dipilih yang menggunakan lampu bertenaga surya sebagai alternatif sumber energi. Selain itu, dibuat tandon-tandon penampung air hujan di sekitar area gazebo untuk memenuhi kebutuhan air di RTH tersebut dan sekitarnya.

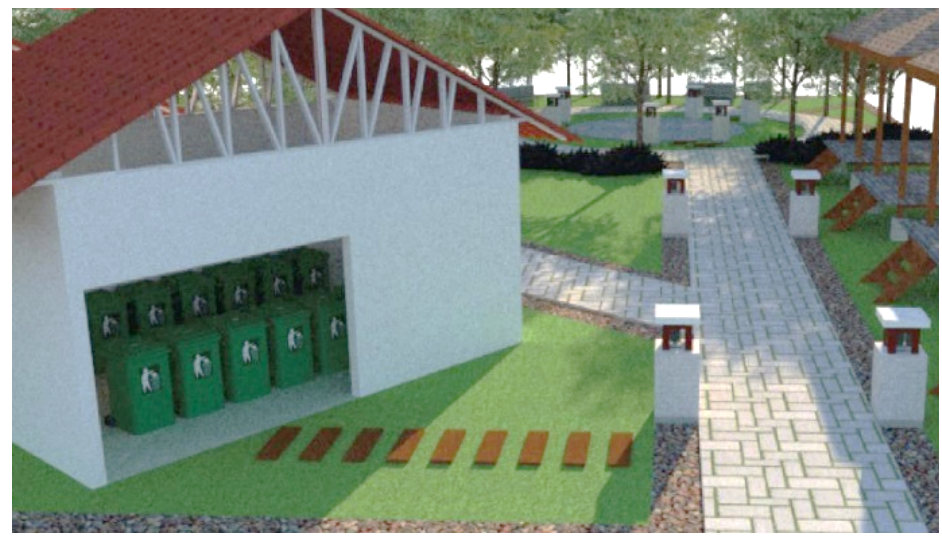

Gambar 4. Bangunan Pengelolaan Sampah

Sumber: Penulis, 2021

- Working with Climate

Agar dapat beradaptasi dengan iklim lokal, bangunan pengelolaan sampah didesain dengan bukaan cross ventilation yang cukup lebar agar distribusi udara lebih sejuk dan segar ke dalam ruangan (Gambar 4). Untuk meminimalisir aroma yang kurang sedap, maka dibutuhkan tanaman yang mampu mengurangi polusi bau di sekitar area bangunan. Tanaman yang dipilih adalah tanaman lidah mertua dan bunga melati karena mudah didapatkan di daerah Batam. Area RTH juga ditanam beberapa jenis pohon lokal seperti pohon kelapa dan pohon Ketapang (Gambar 5). Penyediaan vegetasi-vegetasi tersebut dapat membantu untuk beradaptasi dengan iklim lokal Batam yang tergolong panas.

Selain itu, dengan curah hujan yang cukup tinggi maka dipilihlah material-material yang mampu beradaptasi dengan kondisi tersebut, seperti grass block/ paving block rumput dan batu alam. Salah satu keunggulan paving block rumput adalah kekuatannya. Paving block rumput memiliki material penyusun yang lebih kuat dari paving block pada umumnya dan juga lubang pada paving block rumput membentuk paving block ini agar tidak mudah pecah atau hancur sehingga pemakaiannya dapat jangka panjang. Selain karena material penyusunnya, paving block rumput juga dapat membantu proses penyerapan air tanah. Sehingga bila menggunakan paving block 
rumput, air hujan yang jatuh tidak akan tergenang. Beberapa bagian dari taman juga dihiasi dengan batu alam. Jenis batu alam yang akan digunakan dalam perancangan RTH ini adalah batu andesit. Selain untuk segi estetika, batu andesit memiliki tekstur yang keras sehingga dapat membuat batu lebih tahan lama. Batu andesit juga memiliki ketahanan tinggi terhadap perubahan suhu dan cuaca, sehingga menjadikannya bahan yang ideal untuk digunakan lingkungan outdoor.

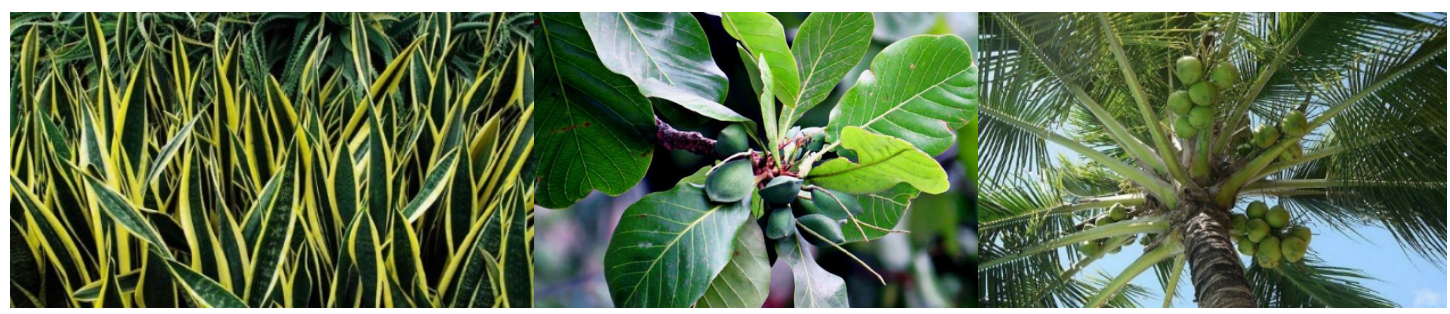

Gambar 5. Pemilihan Jenis Tanaman: Lidah Mertua, Pohon Ketapang, dan Pohon Kelapa Sumber: Google Images, 2021

- Respect for Site

Perencanaan RTH tidak terlepas dengan perencanaan tapak yang dibangun. Guna tetap mempertahankan kondisi tapak, maka desain dibuat mengikuti kondisi eksisting namun untuk mengurangi efek monoton tapak yang datar, diberikan desain yang dinamis melalui kombinasi bentuk pola lingkaran dan garis lurus, serta seluruh area tapak dapat dimanfaatkan.

- Respect for User

Selain harus memerhatikan kondisi lingkungan, perencanaan RTH ini tetap harus memerhatikan pengguna yaitu masyarakat Kampung Tua Tanjung Riau. Kampung Tua Tanjung Riau merupakan salah satu kampung tua di Batam yang masih kental budaya Melayunya, oleh karena itu desain RTH ini tidak lepas dari budaya Melayu. Penggunaan motif pakis paku dalam bangku taman bertujuan untuk tetap menjaga kelestarian budaya Melayu dan menjadi identitas RTH tersebut (Gambar 6).

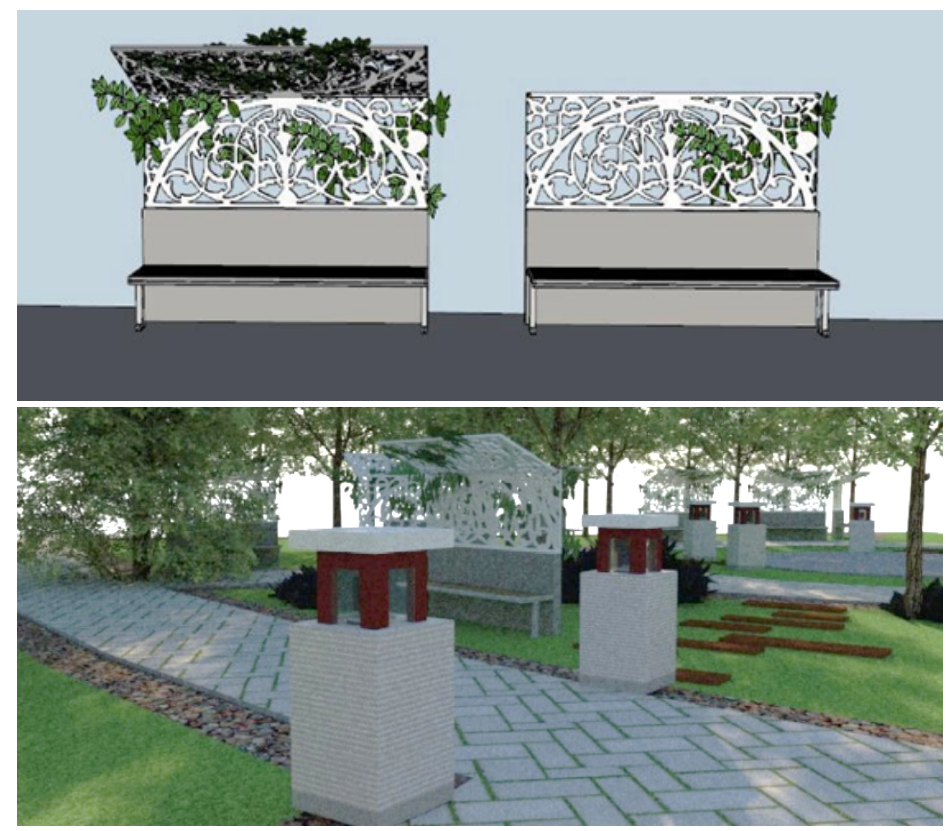

Gambar 6. Pengaplikasian Unsur Melayu dalam Desain Bangku RTH Publik Sumber: Penulis, 2021

61 I JA-Vol.02/No.01, Juni 2021 
- Limiting New Resources

Penggunaan material dalam perancangan RTH ini juga sangat penting. Khususnya penggunaan material lokal yang dapat didaur ulang atau digunakan kembali. Selain itu, material yang tahan lama menjadi hal penting lainnya untuk meminimalisir penggunaan material baru.

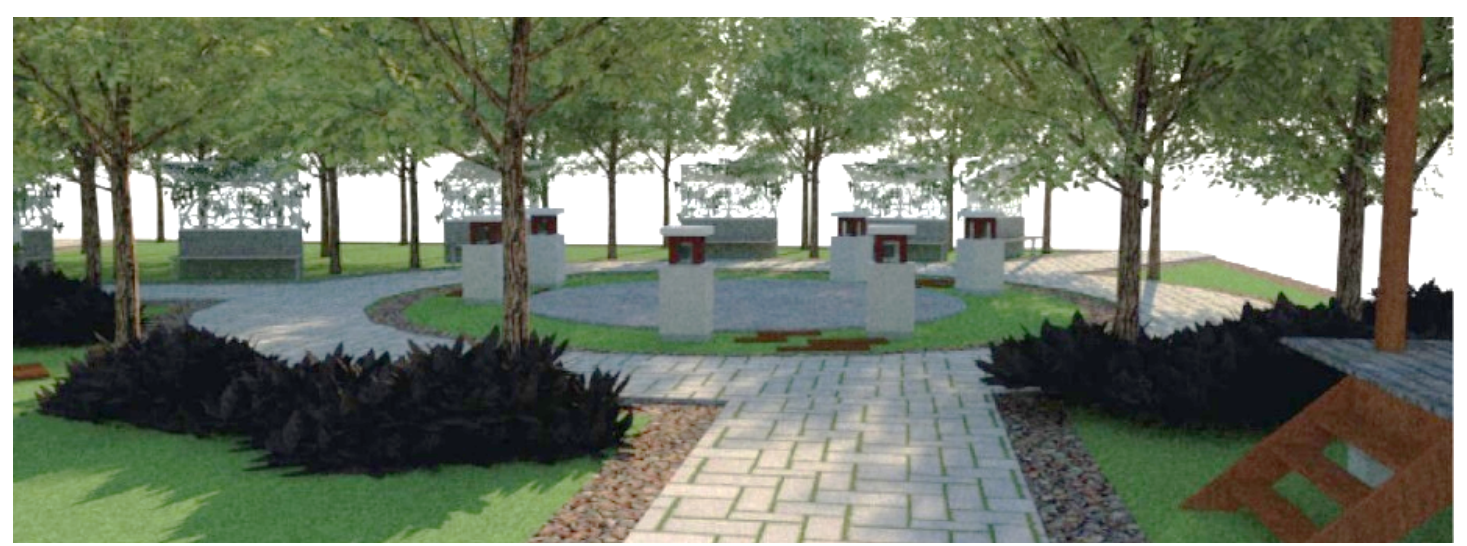

Gambar 7. Pemilihan Material yang Tahan Lama

Sumber: Penulis, 2021

- Holistic

Dengan menerapkan keseluruhan kriteria, maka desain ini diharapkan menjadi desain ruang terbuka hijau publik yang ramah terhadap lingkungan melalui konsep green architecture secara utuh.

\section{Kesimpulan}

Dari uraian hasil dan pembahasan, dapat disimpulkan bahwa penerapan konsep green architecture dapat diwujudkan pada perencanaan RTH di Kampung Tua Tanjung Riau melalui enam kriteria sebagai berikut:

- Hemat energi - penggunaan sinar matahari sebagai alternatif sumber energi listrik dan sumber utama pencahayaan (alami); pemilihan warna lampu yang berpengaruh pada intensitas pencahayaan; penampungan air hujan untuk dapat digunakan kembali di lingkungan setempat.

- Mampu beradaptasi dengan iklim - penggunaan material-material yang tahan cuaca dan iklim setempat; penerapan cross ventilation pada bangunan; pemilihan jenis tanaman lokal.

- Tanggap terhadap tapak - meminimalisir perubahan kondisi eksisting tapak.

- Memenuhi kebutuhan pengguna - penggunaan unsur budaya lokal sebagai ornamen dekorasi, yakni penggunaan ukiran Melayu yang diterapkan di bangku-bangku taman sebagai bentuk pelestarian kearifan lokal.

- Meminimalisir penggunaan material baru - penggunaan material-material lokal yang tahan lama.

Penyediaan ruang terbuka hijau (RTH) publik berkonsep green architecture dengan mengoptimalkan ruang terbuka yang ada di Kampung Tua Tanjung Riau ini dapat memberikan dampak positif bagi lingkungan sekitarnya. Mulai dari menurunkan suhu lokal hingga memperindah kawasan. Namun, kajian lebih mendalam dan detail terhadap desain RTH di kawasan permukiman tersebut perlu dilakukan untuk dapat mewujudkan RTH publik yang ramah lingkungan dan berkelanjutan di kemudian hari. 


\section{Daftar Pustaka}

Aguspriyanti, C. D., Nimita, F., \& Deviana. (2020). Analisis Faktor-Faktor Penyebab Kekumuhan di Permukiman Pesisir Kampung Tua Tanjung Riau. Journal of Architectural Design and Development, 01(02), 176-186. https://doi.org/10.37253/jad.v1i2.1501

Aguspriyanti, C. D., Shevriyanto, B., \& Charlie, C. (2021). Pengaruh Bentuk Pola Persebaran Permukiman Penduduk terhadap RTH di Kampung Tua Tanjung Riau. TEKSTUR: Journal of Architecture, 2(1), 17-22. https://ejurnal.itats.ac.id/tekstur/article/view/1693

Bowler, D. E., Buyung-Ali, L. M., Knight, T. M., \& Pullin, A. S. (2010). A systematic review of evidence for the added benefits to health of exposure to natural environments. $B M C$ Public Health. https://doi.org/10.1186/1471-2458-10-456

Dharmadiatmika, I. M. A. (2017). Konsep Penataan Ruang Terbuka Hijau Publik Di Kota Kecamatan Mengwi , Kabupaten Badung, Provinsi Bali The Concept of Public Green Open Space Structuring in the City of Mengwi Sub-District, Badung Regency, Bali Province. E-Jurnal Arsitektur Lansekap, 3(2), 213-222.

Direktorat Jenderal Penataan Ruang Departemen Pekerjaan Umum. (2008). Pedoman Penyediaan dan Pemanfaatan Ruang Terbuka Hijau di Kawasan Perkotaan.

Hakim, R. (1987). Unsur Dalam Perancangan Arsitektur Landscape. Balai Pustaka.

Hepcan, Ş., Kaplan, A., Özkan, B., Küçükerbaş, E. V., Yiğit, E. M., \& Türel, H. S. (2006). Public space networks as a guide to sustainable urban development and social life: A case study of Muğla, Turkey. International Journal of Sustainable Development and World Ecology. https://doi.org/10.1080/13504500609469687

Mira Dharma, S., \& Aldy, P. (2017). Aplikasi Arsitektur Hijau Pada Ruang Terbuka. 814-825.

Nitdiawati. (2011). Perencanaan Ruang Terbuka Hijau (RTH) Di Jalan Bhayangkara Surakarta. Universitas Sebelas Maret.

Rukayah, S. (2003). PENEKANAN DESAIN ARSITEKTUR ORGANIK DAN GREEN ARCHITECTURE PADA PERANCANGAN PUSAT REKREASI DAN KLUB PEMANCINGAN DI RAWAPENING, KABUPATEN SEMARANG. Jurnal Jurusan Arsitektur.

Sugiyono. (2010). Metode Penelitian Kuantitatif Kuantitatif Dan RND. In Metode Penelitian Kuantitatif Kuantitatif Dan RND.

Vale, B., \& Vale, R. (1991). Green Architecture: Design for a Sustainable Future. Thames and Hudson Ltd. 